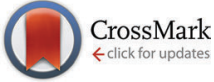

Cite this: Phys. Chem. Chem. Phys., 2016, 18, 23831

Received 4th July 2016, Accepted 4th August 2016 DOI: $10.1039 / \mathrm{c} 6 \mathrm{cp} 04648 \mathrm{~g}$

www.rsc.org/pccp

\title{
Accurate thermodynamic properties of gas phase hydrogen bonded complexes $\dagger$
}

\author{
Anne S. Hansen, Zeina Maroun, Kasper Mackeprang, Benjamin N. Frandsen and \\ Henrik G. Kjaergaard*
}

\begin{abstract}
We have measured the infrared spectra of ethanol-dimethylamine and methanol.dimethylamine complexes in the 299-374 $\mathrm{K}$ temperature range, and have determined the enthalpy of complex formation $(\Delta H)$ to be $-31.1 \pm 2$ and $-29.5 \pm 2 \mathrm{~kJ} \mathrm{~mol}^{-1}$, respectively. The corresponding values of the Gibbs free energy $(\Delta G)$ are determined from the experimental integrated absorbance and a calculated oscillator strength of the $\mathrm{OH}$-stretching vibrational transition to be $4.1 \pm 0.3$ and $3.9 \pm 0.3 \mathrm{~kJ} \mathrm{~mol}^{-1}$ at 302 and $300 \mathrm{~K}$, respectively. The entropy, $\Delta S$ is determined from the values of $\Delta H$ and $\Delta G$ to be $-117 \pm 7$ and $-111 \pm 10 \mathrm{~J}(\mathrm{~mol} \mathrm{~K})^{-1}$ for the ethanol.dimethylamine and methanol-dimethylamine complexes, respectively. The determined $\Delta H$, $\Delta G$ and $\Delta S$ values of the two complexes are similar, as expected by the similarity to their donor molecules ethanol and methanol. Values of $\Delta H, \Delta G$ and $\Delta S$ in chemical reactions are often obtained from quantum chemical calculations. However, these calculated values have limited accuracy and large variations are found using different methods. The accuracy of the present $\Delta H, \Delta G$ and $\Delta S$ values is such that the benchmarking of theoretical methods is possible.
\end{abstract}

\section{Introduction}

Infrared (IR) spectroscopy is an ideal technique for the detection of hydrogen bonds, which induce frequency shifts and changes in the band intensities. ${ }^{1-7}$ The importance of hydrogen bonds has long been acknowledged, as they play an essential role in many chemical and physical processes such as the formation and growth of aerosols. ${ }^{8-12}$ This nucleation is governed by the Gibbs free energy of complex formation $(\Delta G)$, and determination of accurate thermodynamic parameters of complexation is therefore crucial. ${ }^{13}$

Quantum chemical calculations are often used to calculate $\Delta G$ of a process. However, the calculated $\Delta G$ values are associated with large variations based on the method used, ${ }^{14-18}$ and reliable $\Delta G$ values cannot be obtained from these calculations. The variation of $\Delta G$ originates from issues with the calculation of $\Delta H$ and $\Delta S$, which can be associated with large uncertainties. Small differences in the optimised structure, obtained using different methods, generate variations in the calculated $\Delta H$, which to some extent can be overcome by performing high level

Department of Chemistry, University of Copenhagen, Universitetsparken 5, DK-2100 Copenhagen Ø, Denmark.E-mail:hgk@chem.ku.dk; Fax: +45-35320322; Tel: $+45-35320334$

$\dagger$ Electronic supplementary information (ESI) available: Experimental details; temperature and pressure fluctuations; pressures determined from the ideal gas law; $K_{\mathrm{P}}$ and $\Delta H$ values from the individual experiments; optimised structures of the higher energy conformers; calculated thermodynamic parameters; thermodynamic equations; discussion of previous studies. See DOI: 10.1039/c6cp04648g $a b$ initio calculations. The issues related to the calculated $\Delta S$ are more problematic. The uncertainties in $\Delta G$ for weakly bound complexes arise from the very low frequency modes that appear in complexes, and the inherent harmonic treatment of these. These intrinsic problems with $\Delta S$ cannot be solved by using high level $a b$ initio calculations. The standard $a b$ initio calculated thermodynamic properties therefore lack accuracy and accurate experimental values of $\Delta G, \Delta H$ and $\Delta S$ are necessary to facilitate improvements in the theoretical approach. ${ }^{3,18}$

The determination of thermodynamical properties is not new. However, a main issue is the accuracy with which these properties are determined. A variety of purely experimental techniques have been used to determine gas phase $\Delta H$ values. These include nuclear magnetic resonance spectroscopy, ${ }^{19,20}$ microwave spectroscopy, ${ }^{21}$ pressure measurements ${ }^{22-25}$ and IR spectroscopy. ${ }^{24,26-34}$ In most of these studies a van't Hoff type of equation is used to determine $\Delta H{ }^{35}$ For example, the $\Delta H$ value of the complex formation between methanol and trimethylamine has been determined in several different temperature studies. ${ }^{19,24,25,32}$ However, the variation in $\Delta H$ determined from these independent investigations is $\sim 14 \mathrm{~kJ} \mathrm{~mol}^{-1}$ for a $\Delta H$ value that is approximately $-30 \mathrm{~kJ} \mathrm{~mol}^{-1}$. The reason for this discrepancy has not been resolved, and additional temperature experiments are required.

Recently, the Gibbs free energy of complex formation, $\Delta G$, has been determined by combining theoretical calculations and experimental observations. ${ }^{32,34,36,37}$ In these studies, a calculated (e.g. OH-stretching) oscillator strength is used in combination 


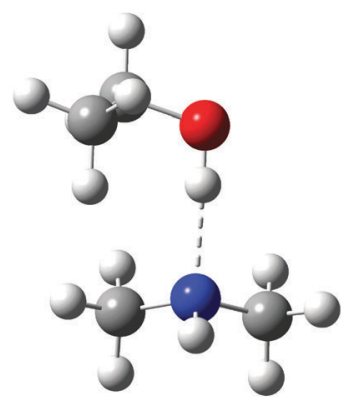

EtOH.DMA

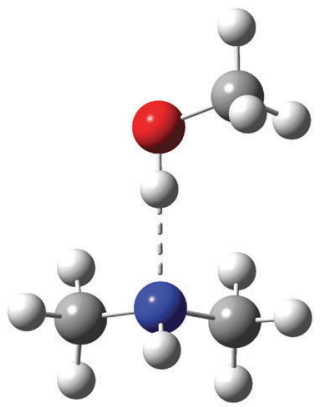

MeOH.DMA
Fig. $1 \mathrm{CCSD}(\mathrm{T})-\mathrm{F} 12 \mathrm{a} / \mathrm{VDZ}-\mathrm{F} 12$ optimised structure of the lowest energy $\mathrm{EtOH} \cdot \mathrm{DMA}$ and $\mathrm{MeOH} \cdot \mathrm{DMA}$ conformers, with binding energies of

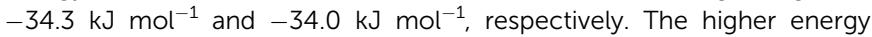
conformers are shown in Fig. $\mathrm{S} 9$ (ESI $\dagger)$.

with an experimental integrated absorbance of the corresponding transition. The calculated oscillator strength is less sensitive to the choice of computational method, compared to $\Delta S$, and some of the issues in calculating the thermodynamic properties are circumvented.

Here, temperature controlled experiments from room temperature (RT) to $374 \mathrm{~K}$ are performed using an experimental setup and procedure aimed at minimising the experimental uncertainties in the determination of the thermodynamic parameters $\Delta H, \Delta G$ and $\Delta S$. The ethanol-dimethylamine (EtOH·DMA) and methanol-dimethylamine (MeOH·DMA) hydrogen bound complexes, Fig. 1, were chosen, as they have been successfully observed and characterised at room temperature and have $K_{\mathrm{P}}$ values of $\sim 0.02$, which facilitate the IR detection of the $\mathrm{OH}$-stretching transition. ${ }^{34,38-41}$ The temperature study provides a $\Delta H$ value via the van't Hoff type equation. We combine the observed integrated absorbance of the $\mathrm{OH}$-stretching vibration with a calculated $\mathrm{OH}$-stretching oscillator strength to determine $K_{\mathrm{P}}$, and hence $\Delta G$. The value of $\Delta S$ follows from the determined $\Delta H$ and $\Delta G$ values. The $\mathrm{OH}$-stretching oscillator strength is calculated using a recently developed Local Mode Perturbation Theory (LMPT) model,${ }^{42-44}$ which is an improvement to the previously used one dimensional (1D) local mode (LM) model. ${ }^{34,45}$

\section{Methods}

\subsection{Gas phase experiments}

$\mathrm{MeOH}$ (Aldrich anhydrous, 99.8\%) and EtOH (Kemetyl anhydrous, 99.9\%) were purified by freeze, pump and thaw cycles. DMA (Aldrich anhydrous, 99+\%) was used without further purification. Spectra were recorded using a VERTEX 70 or VERTEX 80 (Bruker) Fourier transform infrared (FTIR) spectrometer using a $1 \mathrm{~cm}^{-1}$ resolution and 500 scans. The spectrometers were fitted with a $\mathrm{CaF}_{2}$ beam splitter and an MCT detector. The mixture and monomer samples were prepared using a glass vacuum line (J. Young, base pressure of $1 \times 10^{-4}$ Torr) equipped with several Varian and Agilent Technologies Pirani capacitance diaphragm pressure gauges $\left(5 \times 10^{-5}-1500\right.$ mbar, PCG-750).
Spectral subtraction and analyses were performed using OPUS 6.5 and OriginPro 2015. The observed $\mathrm{OH}$-stretching band in each of the complexes was integrated from $3100 \mathrm{~cm}^{-1}$ to $3640 \mathrm{~cm}^{-1}$, Fig. S4 (ESI $\dagger$ ). This might introduce a small error, as some of the intensity comes from the sidebands. However, the intensities of the sidebands are small compared to the intensity of the $\mathrm{OH}$-stretching band, and part of their intensity probably originates from coupling to the strong fundamental $\mathrm{OH}$-stretching transition. Additional experimental details are given in Section $\mathrm{S} 1$ (ESI $\dagger$ ).

The measurements were performed using a $2.4 \mathrm{~m}$ multireflection gas cell (Infrared Analysis, Inc.). The cell was equipped with a heating jacket connected to a Digi-Sense electronic temperature controller (Eutech Instruments Pte Ltd, Model 68900-03) and a Varian PCG-750 pressure gauge. The cell temperature and pressure were monitored throughout all experiments. We recorded spectra at different temperatures, from RT to $374 \mathrm{~K}$. At each temperature, spectra of alcohol + DMA mixtures and the corresponding monomers were recorded and the average cell temperature and pressure were noted. The $2.4 \mathrm{~m}$ gas cell was filled with sample pressure at room temperature, placed in the spectrometer and heated. The cell was heated in steps of $\sim 10 \mathrm{~K}$ from $305 \mathrm{~K}$ to $374 \mathrm{~K}$. This experimental procedure is less tedious than that in previous temperature studies, where a new mixture was prepared for each temperature measurement in an attempt to keep the product of the two monomer pressures fixed. ${ }^{30,32,34}$ To improve accuracy, repeated measurements were performed, see Section $\mathrm{S} 1$ (ESI $\dagger$ ).

Spectra of the alcohol-DMA complexes were obtained by subtracting the individual monomer spectra from the spectrum of the alcohol + DMA mixture, see Fig. $2{ }^{46}$ The monomer spectra used in the subtraction were recorded at a slightly different pressure relative to the pressure of each monomer in the mixture. The monomer spectra were scaled and then subtracted from the spectrum of the alcohol + DMA mixture, and an accurate subtraction was found when a straight baseline was obtained in the regions with clearly assigned monomer absorbance features. The pressure of the individual monomers in the alcohol + DMA mixtures was obtained by multiplying the scaling factor from the spectral subtraction with the monomer pressure of the individual monomer spectra.

In non-RT experiments, the temperature and pressure fluctuations during each measurement were investigated. The cell temperature fluctuated with a maximum of $7 \mathrm{~K}$, while the pressure fluctuations were limited to $\leq 0.5$ Torr. A detailed description and analysis of the temperature and pressure fluctuations in the cell are given in the ESI, $\dagger$ Section S1.2.

\subsection{Thermodynamics and calculations}

The aim of the temperature controlled experiments is to determine $\Delta H . \Delta G$ is related to $\Delta H$ and $\Delta S$, and to $K_{\mathrm{P}}$ by:

$$
\begin{gathered}
\Delta G=\Delta H-T \Delta S, \\
\Delta G=-R T \ln K_{\mathrm{P}},
\end{gathered}
$$



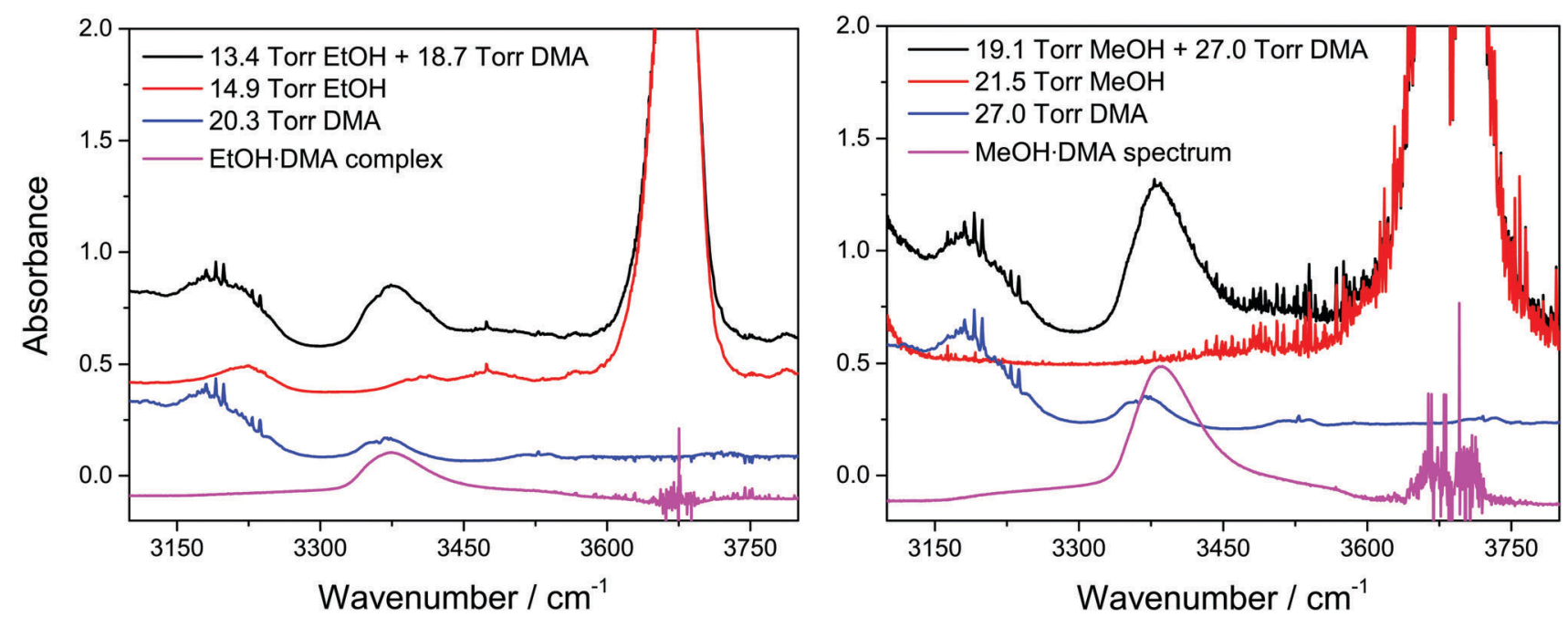

Fig. 2 Spectra of alcohol + DMA mixtures, alcohols, and DMA and the spectra of the EtOH.DMA and MeOH.DMA complexes obtained after spectral subtraction. The spectra have been offset.

where $T$ is the temperature and $R$ is the gas constant. Combining eqn (1) and (2), we obtain a van't Hoff like equation:

$$
\ln K_{\mathrm{P}}=-\frac{\Delta H}{R} \frac{1}{T}+\frac{\Delta S}{R}
$$

If we assume that $\Delta H$ and $\Delta S$ are constant in a given temperature range, then a plot of $\ln K_{\mathrm{P}}$ versus $T^{-1}$ should yield a straight line, from which $\Delta H$ and $\Delta S$ can be determined. ${ }^{35}$

The equilibrium investigated in the present study can be expressed as:

$$
\mathrm{A}+\mathrm{B} \rightleftharpoons \mathrm{C},
$$

where $\mathrm{A}$ and $\mathrm{B}$ are the individual monomers, alcohol and DMA, and $\mathrm{C}$ is the complex. The dimensionless equilibrium constant of complex formation is given by:

$$
K_{\mathrm{P}}=\frac{P_{\mathrm{C}}}{P_{\mathrm{A}} P_{\mathrm{B}}} \times P^{\ominus},
$$

where $P_{\mathrm{C}}$ is the pressure of the complex, $P_{\mathrm{A}}$ is the pressure of monomer A (alcohol), $P_{\mathrm{B}}$ is the pressure of monomer $\mathrm{B}$ (DMA) and $P^{\ominus}$ is the standard pressure of 1 bar. $P_{\mathrm{A}}$ and $P_{\mathrm{B}}$ are determined directly from our measurements. The pressure of the complex is very small, typically less than 1 Torr for these complexes, and measuring it directly is difficult. In addition, the condensation rate of the monomers and the complex is unknown and probably different, which complicates the accurate determination of the pressure of the complex. To circumvent these problems we determine $P_{\mathrm{C}}$ indirectly by: $:^{47,48}$

$$
P_{\mathrm{C}}=2.6935 \times 10^{-9}\left[\mathrm{~K}^{-1} \text { Torr } \mathrm{m} \mathrm{cm}\right] \frac{T \int A(\tilde{\nu}) \mathrm{d} \tilde{\nu}}{f_{\text {calc }} l},
$$

where $\int A(\tilde{\nu}) \mathrm{d} \tilde{\nu}$ is the measured integrated absorbance of the characteristic $\mathrm{OH}$-stretching band, $f_{\text {calc }}$ is the corresponding calculated oscillator strength and $l$ is the optical path length. The calculated oscillator strength used to determine $P_{\mathrm{C}}$ will affect $K_{\mathrm{P}}$ and hence $\Delta G$ (eqn (2)) but has no effect on $\Delta H$, which is determined from the slope of $\ln K_{\mathrm{P}}$ versus $T^{-1}$. Any change in the calculated oscillator strength can simply be expressed as an additional constant on the right hand side of eqn (3) (see the ESI, $\dagger$ Section S2).

The oscillator strength of the $\mathrm{OH}$-stretching vibration in the complex is calculated using an LM approach. ${ }^{49-51}$ We use the LMPT model, which was originally developed to describe donor vibrations of hydrated complexes in which water is the donor unit. ${ }^{42,43}$ The model is based on a three dimensional LM model for the water unit, ${ }^{52}$ and the effect of each of the six intermolecular modes on the donor vibrational modes is included by Rayleigh-Schrödinger perturbation theory, where each intermolecular mode couples to each of the donor vibrational modes through the potential energy surface. The LMPT model has been found to calculate hydrogen bound $\mathrm{OH}$-stretching frequencies that are within $10 \mathrm{~cm}^{-1}$ of experimental values of hydrated complexes, which is much better than the frequencies calculated using a LM model. ${ }^{42,53}$ The LMPT calculated oscillator strengths are also improved. However, the experimental intensities have large uncertainties, which makes it difficult to quantify the LMPT calculated oscillator strengths. ${ }^{43}$ Here, a modified LMPT version is used, in which a two dimensional LM model of the $\mathrm{OH}$-stretching and the $\mathrm{COH}$-bending oscillators is employed, and only the effect of the two most important intermolecular modes is included. Details on the modified LMPT model are given in the ESI, $\dagger$ Section S4. ${ }^{44}$

The structures of the complexes and corresponding monomers were optimised using density functional theory (DFT) with the B3LYP, B3LYP-D3, $\omega$ B97X-D and M06-2X functionals and the Møller Plesset (MP2) method in Gaussian09 $9^{54,55}$ using the aug-cc-pVTZ basis set and the keywords: "opt = verytight" and "integral = ultrafine". Subsequently, a harmonic frequency calculation was performed, with the same options as for the optimisation, to ensure that an energy minimum was found. From the frequency calculations, thermodynamic parameters were calculated using standard statistical mechanics. ${ }^{54,56}$ 
In addition, optimisations were performed using the CCSD(T)-F12a/VDZ-F12 method in Molpro2012 with the default optimisation threshold criteria and the correlation factor: $(1 / \beta) \exp \left(-\beta r_{12}\right)$, where $\beta=0.9 .^{57,58}$ The oscillator strength of the $\mathrm{OH}$-stretching vibration was calculated using the LMPT model, and potential energy and dipole moment surfaces were calculated using the CCSD(T)-F12a/VDZ-F12 method. The potential energy surface was calculated as described in Section S4 (ESI $\dagger$ ) with all single point energies converged to $1 \times 10^{-8}$ a.u. ${ }^{42,43}$ The dipole moments were calculated at the same geometries used to generate the potential energy surface. The finite field approach was used to determine the dipole moments with an applied field of \pm 0.0001 a.u. ${ }^{59}$ All integrals were evaluated numerically using the trapezoidal rule and the Matlab software package. ${ }^{60}$

\section{Results and discussion}

\subsection{The OH-stretching vibration in the complexes}

In Fig. 3, we show vibrational spectra in the OH-stretching region of the EtOH.DMA and MeOH.DMA complexes, recorded at different temperatures. The maximum of the $\mathrm{OH}$-stretching vibration in the EtOH.DMA and $\mathrm{MeOH} \cdot \mathrm{DMA}$ complexes is temperature dependent. At RT, the maximum absorbances are observed at $3374 \mathrm{~cm}^{-1}$ and $3386 \mathrm{~cm}^{-1}$ for EtOH.DMA and $\mathrm{MeOH} \cdot \mathrm{DMA}$, respectively, which shift to $3384 \mathrm{~cm}^{-1}$ and $3394 \mathrm{~cm}^{-1}$ at $374 \mathrm{~K}$. The $\mathrm{OH}$-stretching band maxima at RT are in agreement with previous observations. ${ }^{34,38-41}$ As the temperature increases, the band intensity decreases, which indicates the formation of less complex and a smaller equilibrium constant. At each temperature the integrated absorbance of the $\mathrm{OH}$-stretching transition was determined and combined with a calculated oscillator strength to determine $P_{\mathrm{C}}$. In Fig. 4, $P_{\mathrm{C}}$ determined at each temperature is plotted as a function of the multiplied monomer pressures. Fig. 4 includes the data from all experiments performed for the EtOH.DMA (three) and $\mathrm{MeOH} \cdot \mathrm{DMA}$ (two) complexes, see Section S1 (ESI $\dagger$ ).

For each temperature a straight line passing through zero was fitted to the two or three data points, using the linear least squares fit with weighted error bars, see Sections S1.1 and S5 (ESI $\dagger)$. The equilibrium constants $\left(K_{\mathrm{P}}\right)$ are obtained from the slopes of each fit multiplied by the standard pressure. In Table 1, we summarise the $K_{\mathrm{P}}$ values determined. They range from $\sim 0.2$ to $\sim 0.02$ in the RT to $374 \mathrm{~K}$ temperature range, and decreases by $\sim 25 \%$ with every $10 \mathrm{~K}$ increase in temperature. Throughout the RT measurements, sample condensation and a continuous drop in pressure were observed (Fig. S5, ESI $\dagger$ ), and we chose not to use this data point in the later fits.

The $K_{\mathrm{P}}$ values of 0.19 and 0.21 determined at RT are in reasonable agreement with the value of 0.11 previously determined for the EtOH.DMA and MeOH.DMA complexes at $298 \mathrm{~K}$ and $300 \pm 1 \mathrm{~K}$, respectively. ${ }^{34,40}$ The discrepancy between our determined $K_{\mathrm{P}}$ values and those previously determined arises primarily from differences in the calculated oscillator strengths. In the previous studies, 1D LM OH-stretching oscillator strengths of $2.2 \times 10^{-4}$ (B3LYP/aug-cc-pVTZ) and $1.8 \times 10^{-4}$ (CCSD(T)-F12a/VDZ-F12) were used for EtOH.DMA and MeOH.DMA, respectively. ${ }^{34,40}$ These oscillator strengths are expected to be overestimated compared to experimental values. ${ }^{42,53,61}$ Using the improved LMPT model the calculated $\mathrm{OH}$-stretching oscillator strengths are $1.2 \times 10^{-4}$ and $1.3 \times 10^{-4}$ for EtOH·DMA and MeOH.DMA, respectively, ${ }^{44}$ which are smaller than the 1D LM calculated values. This decrease in $f_{\text {calc }}$ will increase the determined $P_{\mathrm{C}}$, and thereby increase the determined $K_{\mathrm{P}}$ values.

\subsection{Enthalpy of hydrogen bond formation}

In Fig. $5, \ln K_{\mathrm{P}}$ from each data point in Fig. 4 is plotted as a function of $T^{-1}$, and a straight line is fitted to the data. $\Delta H$ is determined from the slope of the linear fit, and is assumed to be temperature independent within this temperature range.
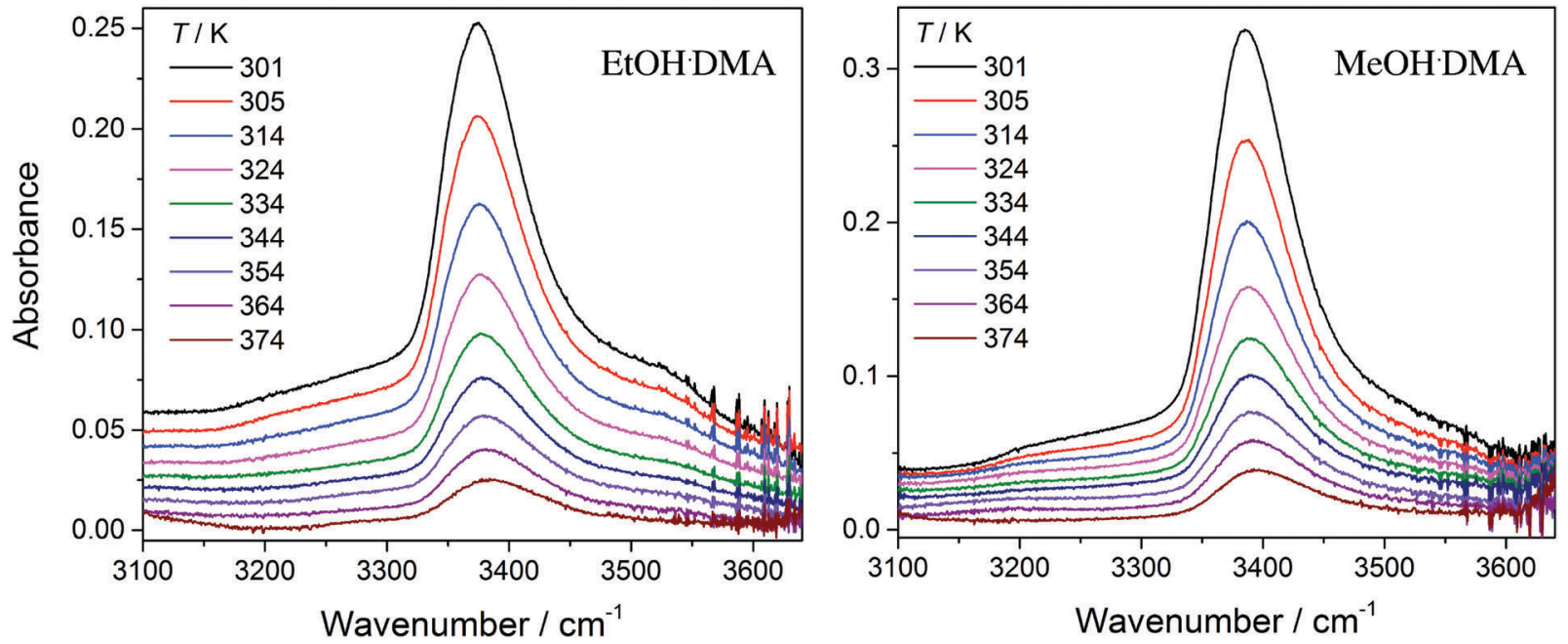

Fig. 3 The $\mathrm{OH}$-stretching vibration in the EtOH.DMA and MeOH.DMA complexes recorded at different temperatures. The spectra have been offset. Experimental details are given in Section S1 (ESI $\dagger)$. 

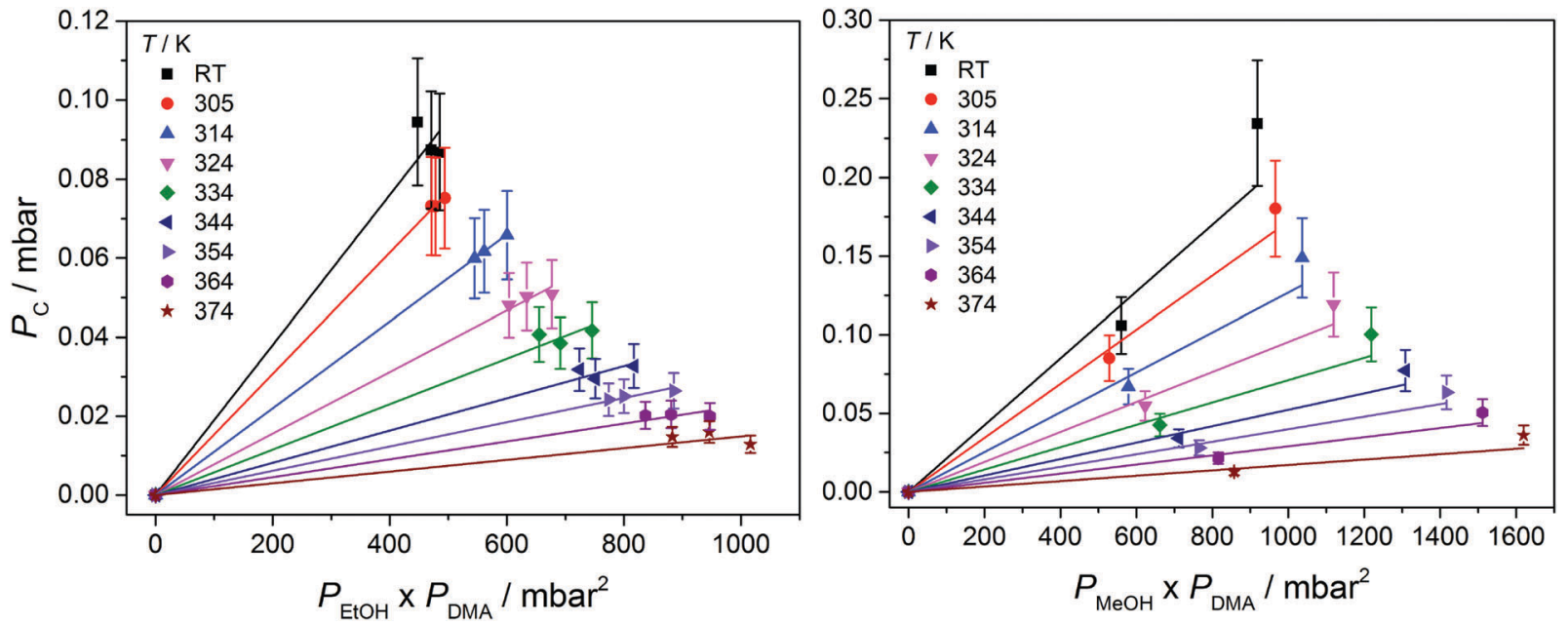

Fig. 4 The pressure of the alcohol.DMA complexes as a function of the multiplied monomer pressures at different temperatures. At RT the values for EtOH.DMA were recorded at 301, 303 and $303 \mathrm{~K}$, and for MeOH.DMA at 299 and $301 \mathrm{~K}$.

Table 1 Determined equilibrium constants $\left(K_{\mathrm{P}}\right)$ and Gibbs free energies $\left(\Delta G\right.$ in $\left.\mathrm{kJ} \mathrm{mol}^{-1}\right)$ for the EtOH.DMA and MeOH.DMA complexes at different temperatures ( $T$ in $\mathrm{K})$

\begin{tabular}{|c|c|c|c|c|}
\hline \multirow[b]{2}{*}{$T$} & \multicolumn{2}{|l|}{$\mathrm{EtOH} \cdot \mathrm{DMA}^{a}$} & \multicolumn{2}{|l|}{ MeOH$\cdot \mathrm{DMA}^{b}$} \\
\hline & $K_{\mathrm{P}}$ & $\Delta G$ & $K_{\mathrm{P}}$ & $\Delta G$ \\
\hline RT & $19.0 \times 10^{-2}$ & 4.17 & $21.2 \times 10^{-2}$ & 3.87 \\
\hline 305 & $15.3 \times 10^{-2}$ & 4.77 & $17.2 \times 10^{-2}$ & 4.47 \\
\hline 314 & $11.0 \times 10^{-2}$ & 5.76 & $12.7 \times 10^{-2}$ & 5.39 \\
\hline 324 & $7.79 \times 10^{-2}$ & 6.87 & $9.55 \times 10^{-2}$ & 6.33 \\
\hline 334 & $5.76 \times 10^{-2}$ & 7.92 & $7.12 \times 10^{-2}$ & 7.33 \\
\hline 344 & $4.09 \times 10^{-2}$ & 9.13 & $5.23 \times 10^{-2}$ & 8.44 \\
\hline 354 & $3.08 \times 10^{-2}$ & 10.2 & $3.99 \times 10^{-2}$ & 9.48 \\
\hline 364 & $2.27 \times 10^{-2}$ & 11.4 & $2.91 \times 10^{-2}$ & 10.7 \\
\hline 374 & $1.49 \times 10^{-2}$ & 13.1 & $1.72 \times 10^{-2}$ & 12.6 \\
\hline
\end{tabular}

${ }^{a}$ An LMPT $f_{\text {calc }}$ value of $1.22 \times 10^{-4}$ was used. The average RT value is $302 \mathrm{~K} .{ }^{b}$ An LMPT $f_{\text {calc }}$ value of $1.27 \times 10^{-4}$ was used. The average RT value is $300 \mathrm{~K}$.
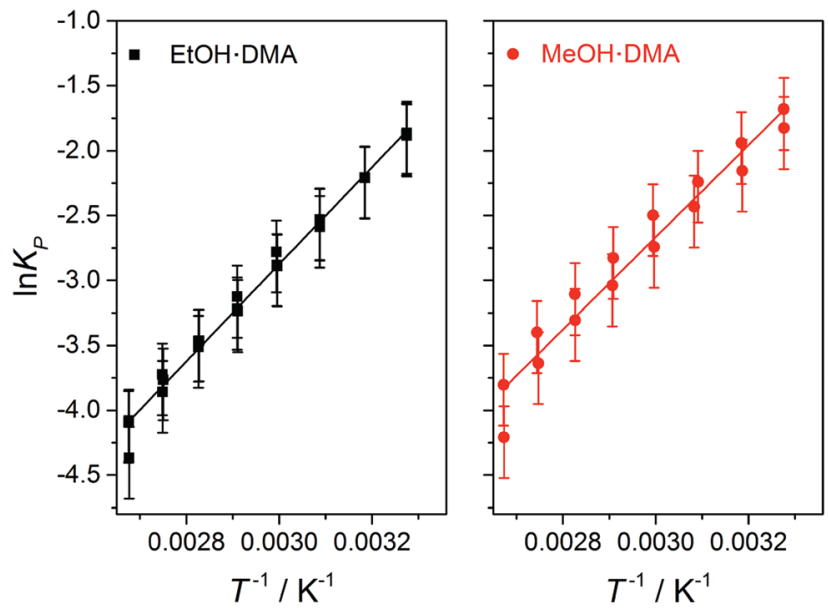

Fig. 5 The $\ln K_{\mathrm{P}}$ versus $T^{-1}$ plot for the EtOH.DMA (black squares, left) and $M e O H \cdot D M A$ (red circles, right) complexes. The slope of the fit is $-\Delta H / R$, which is $3742 \pm 247 \mathrm{~K}^{-1}$ and $3554 \pm 300 \mathrm{~K}^{-1}$ for the EtOH.DMA and $\mathrm{MeOH} \cdot \mathrm{DMA}$ complexes, respectively.
Table 2 Experimentally determined enthalpies of complexation $(\Delta H$ in $\mathrm{kJ} \mathrm{mol}^{-1}$ ) for the EtOH.DMA and MeOH.DMA complexes. The experimental temperature range is given ( $T$ in $\mathrm{K}$ )

\begin{tabular}{llll}
\hline Complex & Method & $T$ & $-\Delta H$ \\
\hline EtOH·DMA & This work $^{a}$ & $305-374$ & 31.1 \\
MeOH·DMA & & & \\
& This work $^{a}$ & $305-374$ & 29.5 \\
& IR $^{b}$ & $298-358$ & 33.1 \\
& Pressure $^{c}$ & $298-318$ & 25.9
\end{tabular}

${ }^{a}$ Uncertainty $\pm 2 \mathrm{~kJ} \mathrm{~mol}^{-1} .{ }^{b}$ Data from ref. 34 , but fitting $\ln \left(T \int A(\tilde{\nu}) \mathrm{d} \tilde{\nu}\right)$ versus $T^{-1}$ rather than $\ln \left(\int A(\tilde{\nu}) \mathrm{d} \tilde{\nu}\right)$ versus $T^{-1} \cdot{ }^{c}$ Ref. 25 , an uncertainty of $\pm 1 \mathrm{~kJ} \mathrm{~mol}^{-1}$.

We find $\Delta H$ values of $-31.1 \pm 2 \mathrm{~kJ} \mathrm{~mol}^{-1}$ and $-29.5 \pm 2 \mathrm{~kJ} \mathrm{~mol}^{-1}$ for the EtOH·DMA and MeOH.DMA complexes, respectively. If we include the room temperature data we get $\Delta H$ values of $-31.5 \mathrm{~kJ} \mathrm{~mol}^{-1}$ and $-29.4 \mathrm{~kJ} \mathrm{~mol}^{-1}$ for the EtOH.DMA and $\mathrm{MeOH} \cdot \mathrm{DMA}$ complexes, respectively (Fig. S14, ESI $\dagger$ ). To check a possible temperature dependence of $\Delta H$, we divided our data into two ranges, 305-334 $\mathrm{K}$ and 344-374 $\mathrm{K}$ (Section S6 and Fig. S15, ESI $\dagger$ ). However, due to the small number of data points in each range, the standard error in each range is larger than the difference in the $\Delta H$ values and a temperature dependence of $\Delta H$ could not be concluded.

In Table 2, we summarise our determined $\Delta H$ values for the EtOH.DMA and MeOH.DMA complexes, and compare with those previously determined. ${ }^{25,34}$ Our determined $\Delta H$ values for the EtOH·DMA and MeOH.DMA complexes are roughly the same. This is not surprising as $\Delta H$ is essentially the binding strength of the complexes, and the calculated binding energy of the EtOH·DMA and MeOH·DMA complexes is similar. ${ }^{34,40}$ However, differences in $\Delta S$ might be expected, due to the larger number of vibrations in EtOH.

The result labelled "IR" in Table 2 refers to a previous temperature controlled experiment, which we have corrected for a missing temperature dependence. This changes the 
original value of $-35.8 \mathrm{~kJ} \mathrm{~mol}^{-1}$ to $-33.1 \mathrm{~kJ} \mathrm{~mol}^{-1}$ (see Section S7.1, ESI $\dagger) .{ }^{34}$ In these experiments, the $P_{\mathrm{A}} P_{\mathrm{B}}$ product was attempted kept fixed at all temperatures, which makes the elevated temperature measurements much more complicated. ${ }^{34}$

The result labelled "Pressure" in Table 2 refers to a previous experiment where $\Delta H$ was determined from changes in pressure. $^{25}$ Two chambers, equipped with mercury manometers, were connected with a valve. ${ }^{25}$ One container was filled with $\mathrm{MeOH}$ vapour and the other with DMA vapour. The valve connecting the two containers was opened, and the compounds were mixed, forming the MeOH·DMA complex. The decrease in pressure was assigned to complex formation, and $K_{\mathrm{P}}$ was determined. This procedure was repeated at different temperatures, and the determined $K_{\mathrm{P}}$ values were plotted against $T^{-1}$. A $\Delta H$ value of $-25.9 \pm 1 \mathrm{~kJ} \mathrm{~mol}^{-1}$ was determined, where the standard deviation is related to the goodness of the fit without including the errors of the individual data points. The fact that condensation of the complex and monomers might occur at different rates is not taken into account, and would lead to an increased $K_{\mathrm{P}}$ value. Any variation in condensation with temperature would lead to changes in the determined $\Delta H$ value.

\subsection{Gibbs free energy and entropy of complexation}

In Table 3, we compare our $\Delta G$ values, obtained with both 1D LM and LMPT calculated oscillator strengths, with those previously determined. ${ }^{34,40}$ The previous experimental results, given in brackets in Table 3, have been improved with better band integration and use of our present high level LMPT calculated oscillator strength (Section S7.2, ESI $\dagger$ ). The use of the LMPT model reduces the 1D LM oscillator strength by about $30 \%$, which for both complexes leads to a decrease in the determined $\Delta G$ values. ${ }^{44}$ Previously, both the fundamental $\mathrm{OH}$-stretching and second overtone of the $\mathrm{NH}_{\mathrm{f}}$-stretching vibrations were detected, and used to determine independent $\Delta G$ values. ${ }^{34,40}$ In the present study, we have calculated the 1D LM and LMPT XH-stretching oscillator strengths of both the fundamental $\mathrm{OH}$-stretching and second overtone $\mathrm{NH}_{\mathrm{f}}$-stretching vibrations using the $\operatorname{CCSD}(\mathrm{T})-\mathrm{F} 12 \mathrm{a} / \mathrm{VDZ}-\mathrm{F} 12$ method. The $\mathrm{NH}_{\mathrm{f}}$-stretching vibration is relatively unaffected by the complexation, and therefore easier to calculate than the hydrogen bound $\mathrm{OH}$-stretching vibration. This is reflected in the similar LM and LMPT $\mathrm{NH}_{\mathrm{f}}$-stretching oscillator strengths. The LMPT oscillator strengths lead to $\Delta G$ values of $3.54 \mathrm{~kJ} \mathrm{~mol}^{-1}(299 \mathrm{~K})$ and $4.50 \mathrm{~kJ} \mathrm{~mol}^{-1}(297 \mathrm{~K})$ for EtOH.DMA and MeOH.DMA,

Table 3 Gibbs free energies ( $\Delta G$ in $\mathrm{kJ} \mathrm{mol}^{-1}$ ) for the EtOH.DMA and $\mathrm{MeOH}$.DMA complexes, determined by combining a measured integrated absorbance and a calculated oscillator strength

\begin{tabular}{lcr}
\hline & 1D LM & LMPT $^{c}$ \\
\hline EtOH·DMA $^{a}$ & 4.93 & $4.17(4.68)$ \\
MeOH·DMA $^{b}$ & 4.39 & $3.87(4.64)$ \\
& & \\
${ }^{a}$ 1D LM and LMPT $f$ values of $1.66 \times 10^{-4}$ and $1.22 \times 10^{-4}$ were used, \\
respectively. ${ }^{b}$ 1D LM and LMPT $f$ values of $1.75 \times 10^{-4}$ and $1.27 \times 10^{-4}$ \\
were used, respectively. ${ }^{c}$ The values in parentheses are obtained using \\
the experiments in ref. 34 and 40, with improved integration and \\
oscillator strengths.
\end{tabular}

Table 4 Entropies of complexation $\left(\Delta S\right.$ in $\mathrm{J}\left(\mathrm{mol} \mathrm{K}^{-1}\right)$ for the EtOH.DMA and $\mathrm{MeOH} \cdot \mathrm{DMA}$ complexes

\begin{tabular}{llc}
\hline Complex & Method & $-\Delta S$ \\
\hline EtOH·DMA & This work & $117 \pm 7$ \\
MeOH·DMA & This work & $111 \pm 10$ \\
& Pressure $^{a}$ & $83 \pm 3$ \\
${ }^{a}$ From pressure measurements in ref. 25. & \\
\hline
\end{tabular}

respectively, from the second overtone $\mathrm{NH}_{\mathrm{f}}$-stretching transitions (Table S7, ESI $\dagger$ ). The small difference in temperature between the previous and present experiments will not affect $\Delta G$ more than a few percent (Table 1). With our LMPT oscillator strengths, the presently and the previously determined $\Delta G$ values for the alcohol-DMA complexes are within $0.8 \mathrm{~kJ} \mathrm{~mol}^{-1} \cdot{ }^{34,40} \mathrm{We}$ also find that the determined $\Delta G$ values for the alcohol-DMA complexes obtained from the $\mathrm{OH}$ - and $\mathrm{NH}_{\mathrm{f}}$-stretching transitions are within approximately $0.6 \mathrm{~kJ} \mathrm{~mol}^{-1}$ of each other, which is significantly less than the variation obtained from purely quantum chemically calculated $\Delta G$ values. ${ }^{14-18,34,40}$

We use the $\Delta H$ values given in Table 2 in combination with the $\Delta G$ values in Table 3 to determine the $\Delta S$ values given in Table 4. The uncertainty of $\Delta H$ gives an uncertainty of $\pm 7 \mathrm{~J}(\mathrm{~mol} \mathrm{~K})^{-1}$ and $\pm 10 \mathrm{~J}(\mathrm{~mol} \mathrm{~K})^{-1}$ in $\Delta S$. Our $\Delta S$ value for the $\mathrm{MeOH} \cdot \mathrm{DMA}$ complex of $-111 \pm 10 \mathrm{~J}(\mathrm{~mol} \mathrm{~K})^{-1}$ is significantly larger than the previous $\Delta S$ value of $-83 \mathrm{~J}(\mathrm{~mol} \mathrm{~K})^{-1}$, which has been determined from pressure experiments. ${ }^{25}$ Our determined $\Delta S$ value depends on the calculated oscillator strength. However, for our determined $\Delta S$ value to be $30 \mathrm{~J}$ (mol K$)^{-1}$ lower, the fundamental $\mathrm{OH}$-stretching oscillator strength would have to be $3.3 \times 10^{-5}$. This value is a factor of 4 smaller than our LMPT calculated value of $1.3 \times 10^{-4}$. This difference is much larger than the expected uncertainty of the LMPT model. For example, the LMPT calculated oscillator strength of the fundamental bound $\mathrm{OH}_{\mathrm{b}}$-stretching transition in the water dimer is $4.1 \times 10^{-5}$, which compares well with experimental values of $2.7-4.3 \times 10^{-5}$ and a full dimensional (VPT2) calculated value of $2.8 \times 10^{-5} .43,53,61,62$ We believe that the previous $\Delta S$ value for MeOH-DMA has significantly larger uncertainty than stated. Our determined $\Delta S$ values are similar to the entropy of vaporisation $\left(\Delta_{\mathrm{vap}} S\right)$ for $\mathrm{MeOH}$ and EtOH, which is perhaps not surprising. ${ }^{35}$

\subsection{Calculated thermodynamic properties}

In Table 5, calculated thermodynamic parameter, using a few common $a b$ initio and DFT methods, are summarised for the lowest energy EtOH·DMA and MeOH·DMA conformers. The CCSD(T)-F12a/VDZ-F12 electronic energy and the DFT thermodynamic corrections were combined to calculate thermodynamic parameters, denoted F12//DFT. The B3LYP calculated $\Delta H$ values are substantially higher than those calculated using all other methods due to its lack of dispersion. For all other methods the variation in $\Delta H$ is $4.5 \mathrm{~kJ} \mathrm{~mol}^{-1}$ or about $15 \%$. The variations in calculated $\Delta S$ are less than $10 \%$, if we exclude the B3LYP results, which lead to a $T \Delta S$ variation of up to $4 \mathrm{~kJ} \mathrm{~mol}^{-1}$ at $374 \mathrm{~K}$. The variation in $\Delta G$, excluding the B3LYP results, is 
Table 5 Calculated $\Delta G\left(\mathrm{~kJ} \mathrm{~mol}^{-1}\right), \Delta H\left(\mathrm{~kJ} \mathrm{~mol}^{-1}\right), \Delta S\left(\mathrm{~J}(\mathrm{~mol} \mathrm{~K})^{-1}\right)$ and $K_{\mathrm{P}}$ values at $298.15 \mathrm{~K}$ for the EtOH.DMA and MeOH.DMA complexes ${ }^{a}$

\begin{tabular}{|c|c|c|c|c|c|c|c|c|}
\hline & \multicolumn{4}{|c|}{ EtOH·DMA } & \multicolumn{4}{|c|}{ MeOH·DMA } \\
\hline & $\Delta G$ & $-\Delta H$ & $-\Delta S$ & $K_{\mathrm{P}}$ & $\Delta G$ & $-\Delta H$ & $-\Delta S$ & $K_{\mathrm{P}}$ \\
\hline B3LYP & 12.4 & 18.2 & 102 & $6.77 \times 10^{-3}$ & 10.5 & 19.8 & 102 & $1.42 \times 10^{-2}$ \\
\hline B3LYP-D3 & 5.72 & 29.3 & 118 & $9.97 \times 10^{-2}$ & 3.56 & 29.2 & 110 & $2.38 \times 10^{-1}$ \\
\hline$\omega B 97 X-D$ & 6.73 & 29.3 & 120 & $6.62 \times 10^{-2}$ & 5.52 & 28.3 & 113 & $1.08 \times 10^{-1}$ \\
\hline M06-2X & 11.6 & 27.4 & 131 & $9.32 \times 10^{-3}$ & 7.27 & 27.3 & 116 & $5.33 \times 10^{-2}$ \\
\hline MP2 & 4.00 & 31.6 & 120 & $2.00 \times 10^{-1}$ & 3.01 & 30.7 & 113 & $2.97 \times 10^{-1}$ \\
\hline F12//B3LYP & 3.22 & 27.3 & 102 & $2.72 \times 10^{-1}$ & 3.40 & 27.0 & 102 & $2.53 \times 10^{-1}$ \\
\hline F12//B3LYP-D3 & 7.91 & 27.1 & 118 & $4.12 \times 10^{-2}$ & 5.93 & 26.8 & 110 & $9.13 \times 10^{-2}$ \\
\hline 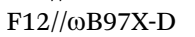 & 8.74 & 27.3 & 121 & $2.94 \times 10^{-2}$ & 6.92 & 26.9 & 113 & $6.14 \times 10^{-2}$ \\
\hline F12//M06-2X & 11.5 & 27.5 & 131 & $9.54 \times 10^{-3}$ & 7.27 & 27.3 & 116 & $5.31 \times 10^{-2}$ \\
\hline Experimental $^{b}$ & 4.17 & 31.1 & 117 & $1.90 \times 10^{-1}$ & 3.87 & 29.5 & 111 & $2.12 \times 10^{-1}$ \\
\hline Experimental $^{c}$ & - & - & - & - & 1.25 & 25.9 & 83 & $5.9 \times 10^{-1}$ \\
\hline
\end{tabular}

$7.5 \mathrm{~kJ} \mathrm{~mol}^{-1}$ and $4.3 \mathrm{~kJ} \mathrm{~mol}^{-1}$ for EtOH·DMA and MeOH·DMA, respectively. The measured and calculated $\Delta S$ values of the EtOH.DMA complex are larger than those of the MeOH·DMA complex. This probably arises from the larger number of vibrations and larger flexibility in EtOH; however, the uncertainties are larger than the differences. Overall, we find that the MP2 method predicts the experimentally determined thermodynamic parameters best.

\section{Conclusions}

Thermodynamic parameters of the EtOH·DMA and MeOH·DMA hydrogen bound complexes were determined from measurements of IR spectra in the room temperature (299-303 K) to $374 \mathrm{~K}$ temperature range. The $\mathrm{OH}$-stretching vibration in the complexes was recorded and identified. By relying on spectroscopic techniques to determine the pressure of each of the three compounds in the mixture, we limit the effect that condensation has on the results. From the temperature measurements, purely experimental $\Delta H$ values were determined for the EtOH.DMA and MeOH.DMA complexes. We combine the observed integrated absorbance and a calculated oscillator strength to determine $\Delta G$ at each temperature. As the temperature increases, the $\mathrm{OH}$-stretching band intensity decreases, which indicates the formation of less complex and a decrease in the equilibrium constant. From the determined $\Delta H$ and $\Delta G$ values, $\Delta S$ was determined. The observed differences in thermodynamic parameters between the $\mathrm{EtOH}$ and $\mathrm{MeOH}$ complexes are small and within their uncertainty. The accuracy in the parameters is significantly better than that achieved using typical quantum chemical methods, and the presented results serve as a theoretical benchmark.

\section{Acknowledgements}

We thank Jan H. Jensen and Jimmy C. Kromann for helpful discussions. We acknowledge the financial support from the Danish Council for Independent Research - Natural Sciences, the Danish Center for Scientific Computing, the Center for
Exploitation of Solar Energy funded by the University of Copenhagen and the Department of Chemistry at University of Copenhagen.

\section{References}

1 E. Arunan, G. R. Desiraju, R. A. Klein, J. Sadlej, S. Scheiner, I. Alkorta, D. C. Clary, R. H. Crabtree, J. J. Dennenberg, P. Hobza, H. G. Kjaergaard, A. C. Legon, B. Mennucci and D. J. Nesbitt, Pure Appl. Chem., 2011, 83, 1619-1636.

2 S. Aloisio and J. S. Francisco, Acc. Chem. Res., 2000, 33, 825-830.

3 V. Vaida and J. E. Headrick, J. Phys. Chem. A, 2000, 104, 5401-5412.

4 H. G. Kjaergaard, T. W. Robinson, D. L. Howard, J. S. Daniel, J. E. Headrick and V. Vaida, J. Phys. Chem. A, 2003, 107, 10680-10686.

5 V. Vaida, H. G. Kjaergaard and K. J. Feierabend, Int. Rev. Phys. Chem., 2003, 22, 203-219.

6 J. S. Daniel, S. Solomon, H. G. Kjaergaard and D. P. Schofield, Geophys. Res. Lett., 2004, 31, L06118.

7 W. Klemperer and V. Vaida, Proc. Natl. Acad. Sci. U. S. A., 2006, 103, 10584-10588.

8 J. Kazil, P. Stier, K. Zhang, J. Quaas, S. Kinne, D. O’Donnell, S. Rast, M. Esch, S. Ferrachat, U. Lohmann and J. Feichter, Atmos. Chem. Phys., 2010, 10, 10733-10752.

9 J. Kirkby, J. Curtius, J. Almeida, E. Dunne, J. Duplissy, S. Ehrhart, A. Franchin, S. Gagné, L. Ickes, A. Kürten, A. Kupc, A. Metzger, F. Riccobono, L. Rondo, S. Schobesberger, G. Tsagkogeorgas, D. Wimmer, A. Amorim, F. Bianchi, M. Breitenlechner, A. David, J. Dommen, A. Downard, M. Ehn, R. C. Flagan, S. Haider, A. Hansel, D. Hauser, W. Jud, H. Junninen, F. Kreissl, A. Kvashin, A. Laaksonen, K. Lehtipalo, J. Lima, E. R. Lovejoy, V. Makhmutov, S. Mathot, J. Mikkilä, P. Minginette, S. Mogo, T. Nieminen, A. Onnela, P. Pereira, T. Petäjä, R. Schnitzhofer, J. H. Seinfeld, M. Sipilä, Y. Stozhkov, F. Stratmann, A. Tomé, J. Vanhanen, Y. Viisanen, A. Vrtala, P. E. Wagner, H. Walther, E. Weingartner, H. Wex, P. M. Winkler, K. S. Carslaw, D. R. Worsnop, U. Baltensperger and M. Kulmala, Nature, 2011, 476, 429-433. 
10 R. Zhang, A. Khalizov, L. Wang, M. Hu and W. Xu, Chem. Rev., 2012, 112, 1957-2011.

11 M. Kulmala, J. Kontkanen, H. Junninen, K. Lehtipalo, H. E. Manninen, T. Nieminen, T. Petäjä, M. Sipiä, S. Schobesberger, P. Rantala, A. Franchin, T. Jokinen, E. Järvinen, M. Äijälä, J. Kangasluoma, J. Hakala, P. P. Aalto, P. Paasonen, J. Mikkilä, J. Vanhanen, J. Aalto, H. Hakola, U. Makkonen, T. Ruuskanen, R. L. Mauldin, J. Duplissy, H. Vehkamäki, J. Bäck, A. Kortelainen, I. Riipinen, T. Kurtén, M. V. Johnston, J. N. Smith, M. Ehn, T. F. Mentel, K. E. J. Lehtinen, A. Laaksonen, V.-M. Kerminen and D. R. Worsnop, Science, 2013, 339, 943-946.

12 J. Almeida, S. Schobesberger, A. Kürten, I. K. Ortega, O. Kupiainen-Määttä, A. P. Praplan, A. Adamov, A. Amorim, F. Bianchi, M. Breitenlechner, A. David, J. Dommen, N. M. Donahue, A. Downard, E. Dunne, J. Duplissy, S. Ehrhart, R. C. Flagan, A. Franchin and R. Guida, Nature, 2013, 502, 359-363.

13 I. K. Ortega, O. Kupiainen, T. Kurtén, T. Olenius, O. Wilkman, M. J. McGrath, V. Loukonen and H. Vehkamäki, Atmos. Chem. Phys., 2012, 12, 225-235.

14 F. C. P. IV, M. E. Dunn and G. C. Shields, J. Phys. Chem. A, 2005, 109, 4905-4910.

15 T. Kurtén, M. R. Sundberg, H. Vehkamäki, M. Noppel, J. Blomqvist and M. Kulmala, J. Phys. Chem. A, 2006, 110, 7178-7188.

16 A. B. Nadykto and F. Yu, Chem. Phys. Lett., 2007, 435, 14-18.

17 J. Elm, M. Bilde and K. V. Mikkelsen, J. Chem. Theory Comput., 2012, 8, 2071-2077.

18 N. Bork, L. Du, H. Reiman, T. Kurtén and H. G. Kjaergaard, J. Phys. Chem. A, 2014, 118, 5316-5322.

19 A. D. H. Clague, G. Govil and H. J. Bernstein, Can. J. Chem., 1969, 47, 625-629.

20 G. Govil, A. D. H. Clague and H. J. Bernstein, J. Chem. Phys., 1968, 49, 2821-2825.

21 C. C. Costain and G. P. Srivastava, J. Chem. Phys., 1964, 41, 1620-1627.

22 C. Ling, S. D. Christian and H. E. Affsprung, J. Phys. Chem., 1966, 70, 901-904.

23 C. Ling, S. D. Christian, H. E. Affsprung and R. W. Gray, J. Chem. Soc. A, 1966, 293-296.

24 M. Fild, M. F. Swiniarski and R. R. Holmes, Inorg. Chem., 1970, 9, 839-843.

25 D. J. Millen and G. W. Mines, J. Chem. Soc., Faraday Trans. 2, 1974, 70, 693-699.

26 R. G. Inskeep, F. E. Dickson and J. M. Kelliher, J. Mol. Spectrosc., 1960, 4, 477-479.

27 E. Hirano and K. Kozima, Bull. Chem. Soc. Jpn., 1966, 39, 1216-1220.

28 S. D. Christian and E. E. Tucker, J. Phys. Chem., 1970, 74, 214-216.

29 R. K. Thomas, Proc. R. Soc. A, 1971, 322, 137-146.

30 D. L. Howard and H. G. Kjaergaard, Phys. Chem. Chem. Phys., 2008, 10, 4113-4118.

31 B. Michielsen, W. A. Herrebout and B. J. van der Veken, ChemPhysChem, 2007, 8, 1188-1198.
32 L. Du and H. G. Kjaergaard, J. Phys. Chem. A, 2011, 115, 12097-12104.

33 B. Michielsen, J. J. J. Dom, B. J. van der Veken, S. Hesse, M. A. Suhm and W. A. Herrebout, Phys. Chem. Chem. Phys, 2012, 14, 6469-6478.

34 L. Du, K. Mackeprang and H. G. Kjaergaard, Phys. Chem. Chem. Phys., 2013, 15, 10194-10206.

35 P. Atkins and J. de Paula, Physical Chemistry, Oxford University Press, 9th edn, 2010.

36 S. Chung and M. Hippler, J. Chem. Phys., 2006, 124, 214316.

37 M. Hippler, J. Chem. Phys., 2007, 127, 084306.

38 D. J. Millen and J. Zabicky, J. Chem. Soc., 1965, 3080-3085.

39 M. A. Hussein and D. J. Millen, J. Chem. Soc., Faraday Trans. 2, 1974, 70, 685-692.

40 A. S. Hansen, L. Du and H. G. Kjaergaard, Phys. Chem. Chem. Phys., 2014, 16, 22882-22891.

41 D. L. Howard and H. G. Kjaergaard, J. Phys. Chem. A, 2006, 110, 9597-9601.

42 K. Mackeprang, H. G. Kjaergaard, T. Salmi, V. Hänninen and L. Halonen, J. Chem. Phys., 2014, 140, 184309.

43 K. Mackeprang, V. Hänninen, L. Halonen and H. G. Kjaergaard, J. Chem. Phys., 2015, 142, 094304.

44 K. Mackeprang and H. G. Kjaergaard, Unpublished results. 45 B. R. Henry and H. G. Kjaergaard, Can. J. Chem., 2002, 80, 1635-1642.

46 L. Du, J. R. Lane and H. G. Kjaergaard, J. Chem. Phys., 2012, 136, 184305.

47 P. Atkins, J. de Paula and R. Friedman, Quanta, Matter, and Change: a molecular approach to physical chemistry, Oxford University Press, 2009.

48 B. I. Niefer, H. G. Kjaergaard and B. R. Henry, J. Chem. Phys., 1993, 99, 5682-5700.

49 B. R. Henry, Acc. Chem. Res., 1977, 10, 207-213.

50 B. R. Henry, Acc. Chem. Res., 1987, 20, 429-435.

51 B. R. Henry and H. G. Kjaergaard, Can. J. Chem., 2002, 80, 1635-1642.

52 H. G. Kjaergaard, B. R. Henry, H. Wei, S. Lefebvre, T. Carrington, O. S. Mortensen and M. L. Sage, J. Chem. Phys., 1994, 100, 6228-6239.

53 H. G. Kjaergaard, A. L. Garden, G. M. Chaban, R. B. Gerber, D. A. Matthews and J. F. Stanton, J. Phys. Chem. A, 2008, 112, 4324-4335.

54 M. J. Frisch, G. W. Trucks, H. B. Schlegel, G. E. Scuseria, M. A. Robb, J. R. Cheeseman, G. Scalmani, V. Barone, B. Mennucci, G. A. Petersson, H. Nakatsuji, M. Caricato, X. Li, H. P. Hratchian, A. F. Izmaylov, J. Bloino, G. Zheng, J. L. Sonnenberg, M. Hada, M. Ehara, K. Toyota, R. Fukuda, J. Hasegawa, M. Ishida, T. Nakajima, Y. Honda, O. Kitao, H. Nakai, T. Vreven, J. A. Montgomery, Jr., J. E. Peralta, F. Ogliaro, M. Bearpark, J. J. Heyd, E. Brothers, K. N. Kudin, V. N. Staroverov, R. Kobayashi, J. Normand, K. Raghavachari, A. Rendell, J. C. Burant, S. S. Iyengar, J. Tomasi, M. Cossi, N. Rega, J. M. Millam, M. Klene, J. E. Knox, J. B. Cross, V. Bakken, C. Adamo, J. Jaramillo, R. Gomperts, R. E. Stratmann, O. Yazyev, A. J. Austin, R. Cammi, C. Pomelli, J. W. Ochterski, R. L. Martin, K. Morokuma, V. G. Zakrzewski, 
G. A. Voth, P. Salvador, J. J. Dannenberg, S. Dapprich, A. D. Daniels, Ã. Farkas, J. B. Foresman, J. V. Ortiz, J. Cioslowski and D. J. Fox, Gaussian 09 Revision D.01, Gaussian Inc., Wallingford CT, 2009.

55 R. Dennington, T. Keith and J. Millam, GaussView Version 5, Semichem Inc., Shawnee Mission KS, 2009.

56 V. Vaida and J. E. Headrick, J. Phys. Chem. A, 2000, 104, 5401-5412.

57 H.-J. Werner, P. J. Knowles, G. Knizia, F. R. Manby, M. Schütz, P. Celani, T. Korona, R. Lindh, A. Mitrushenkov, G. Rauhut, K. R. Shamasundar, T. B. Adler, R. D. Amos, A. Bernhardsson, A. Berning, D. L. Cooper, M. J. O. Deegan, A. J. Dobbyn, F. Eckert, E. Goll, C. Hampel, A. Hesselmann, G. Hetzer, T. Hrenar, G. Jansen, C. Köppl, Y. Liu, A. W. Lloyd, R. A. Mata, A. J. May, S. J. McNicholas, W. Meyer, M. E. Mura, A. Nicklass, D. P. O’Neill,
P. Palmieri, D. Peng, K. Pflüger, R. Pitzer, M. Reiher, T. Shiozaki, H. Stoll, A. J. Stone, R. Tarroni, T. Thorsteinsson and M. Wang, MOLPRO, version 2012.1, a package of ab initio programs, 2012, see http://www.molpro.net.

58 H.-J. Werner, P. J. Knowles, G. Knizia, F. R. Manby and M. Schütz, Wiley Interdiscip. Rev.: Comput. Mol. Sci., 2012, 2, 242-253.

59 B. J. Miller, J. R. Lane and H. G. Kjaergaard, Phys. Chem. Chem. Phys., 2011, 13, 14183-14193.

60 MATLAB and Statistics Toolbox Release R2013a, The MathWorks Inc., Natick, Massachusetts, United States.

61 K. Kuyanov-Prozument, M. Y. Choi and A. F. Vilesov, J. Chem. Phys., 2010, 132, 014304.

62 J. Ceponkus, P. Uvdal and B. Nelander, J. Phys. Chem. A, 2008, 112, 3921-3926. 